Produto \& Produção, vol. 13 n. 2, p. 106-132, jun. 2012

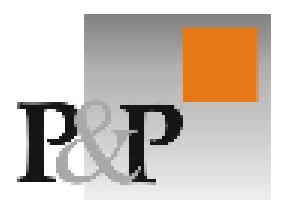

\title{
Um estudo de caso sobre gestão de portfólio de produtos e apoio à decisão multicritério
}

Recebido em 20/12/2011. Aceito em 06/03/2012.

\author{
Sandra Rolim Ensslin \\ Universidade Federal de Santa Catarina - UFSC \\ sensslin@mbox1.ufsc.br
}

\author{
Marcel Viana de Souza \\ Universidade Federal de Santa Catarina - UFSC \\ marcel viana@hotmail.com
}

\section{Leonardo Ensslin \\ Universidade Federal de Santa Catarina - UFSC \\ leonardoensslin@gmail.com}

Organizações onde a inovação, a agilidade e flexibilidade, se constituem em fatores competitivos relevantes, a Gestão de Portfólio de Produtos (GPP) impacta diretamente em seus objetivos estratégicos. Em relação ao meio externo, sua atuação é essencial para que as necessidades dos consumidores sejam melhor atendidas. Ao mesmo tempo, no que tange ao meio interno, a GPP deve ter participação na simplificação dos processos, disponibilizando uma flexibilidade adequada para atender às necessidades dos clientes. Neste ambiente é desenvolvida a presente pesquisa onde o objetivo é construir um modelo de apoio à decisão que evidencie as consequências das decisões tomadas. Por se tratar de um contexto complexo, onde o decisor necessita que seu entendimento seja expandido, será utilizada a metodologia MCDA-C, auxiliando o decisor a construir o modelo personalizado a seus valores e preferências. A metodologia permitiu visualizar os critérios que devem ser tidos em conta durante o desenvolvimento de produtos, apoiando a decisão na elaboração de portfólio de produtos, aperfeiçoamento de propostas, bem como permitir a mensuração ordinal e cardinal do desempenho do portfólio, permitindo a comparabilidade e ordenação dentre as demais propostas. Este artigo ilustra o processo para uma empresa de eletrodomésticos, focando na área de Marketing.

Palavras-chave: Portfólio de Produtos, MCDA-C, Decisão, Multicritério.

Organizations where innovation, agility and flexibility, constitute significant competitive factors, the product portfolio management (PPM) has a direct impact on your strategic goals. In relation to the external environment, its performance is essential to consumers' needs are best met. At the same time, with respect to the 
internal environment, the PPM must be involved in simplifying the process by providing adequate flexibility to meet customer needs. This environment is designed to present research where the goal is to build a model of decision support showing the consequences of decisions. Because it is a complex context, where the decision maker needs to be expanded his understanding, will be used MCDA-C, helping the decision maker to build your custom template to their values and preferences. The methodology enabled visualize the criteria that must be taken into account during product development, assisting in the formulation of product portfolio, improving proposals and allow the ordinal and cardinal measurement of the portfolio performance, enabling the comparison and ranking among other proposals. This article illustrates the process for an appliance company, focusing on the area of Marketing.

Keywords: Product Portfolio, MCDA-C, Decision, Multicriteria.

\section{INTRODUÇÃO}

A gestão de projetos tradicional concentra-se basicamente na eficiência, no desempenho operacional, no tempo e nas metas de orçamento. No entanto, hoje com um ambiente dinâmico de negócios e a competição global é necessário encontrar novas maneiras de fazer projetos que possuam armas competitivas mais poderosas (EISENHARDT; BROWN, 1998).

Conforme mencionam Agard e Kusiak (2004), uma arma poderosa de competitividade das empresas está ligada à fabricação de produtos diversificados para satisfazer as necessidades de seus clientes. Contudo, para a realização desse objetivo, duas questões importantes devem ser explanadas. A primeira diz respeito à diversidade adequada para um determinado mercado, ao passo que a segunda está relacionada à gestão e fabricação de produtos dentro de um tempo de espera aceitável e com um custo competitivo.

Jiao e Tseng (1999) sugerem que a variedade funcional (relacionada à satisfação do consumidor) deve ser promovida na fase de desenvolvimento do produto, e as variáveis técnicas, relacionados com a complexidade de fabricação e custo de produção devem ser reduzidas.

Em contrapartida ao oferecimento de produtos genéricos que correspondem a uma média da satisfação das necessidades de vários clientes, as empresas estão perseguindo uma estratégia de customização, que se preocupa em oferecer produtos com foco no cliente, com um elevado grau de individualidade. Entretanto, enquanto uma estratégia de alta variedade pode ser eficaz para o destaque das empresas perante seus concorrentes, ela, inevitavelmente, aumenta a complexidade fabril.

Cumpre acrescentar ainda que uma grande variedade de produtos pode gerar certa confusão ao cliente, devido à elevada complexidade envolvida ao fazer uma escolha.

Logo, o objetivo geral deste artigo é propor uma metodologia que possibilite identificar, mensurar e integrar as dimensões julgadas pelo decisor como necessárias e suficientes para avaliar a gestão do portfólio de produtos (GPP) da organização. Uma vez explicitados os fatores relevantes com suas escalas, será possível visualizar gráfica e numericamente o diagnóstico da situação atual, assim 
como gerar processo para aperfeiçoar o portfólio e fazer as recomendações necessárias.

Para alcançar os objetivos estabelecidos, os autores selecionam a Metodologia Multi-criteria Decision Aid - Constructivist (MCDA-C) ou Metodologia de Multicritério de Apoio à Decisão - Construtivista por suas características construtivistas, particularmente quanto a: (i) capacidade de promover o conhecimento dos atores, quanto ao contexto que se pretende aperfeiçoar; (ii) capacidade para estruturar e avaliar as dimensões consideradas relevantes por estes atores, dando mais confiabilidade nos resultados (CÁÑEZ; GARFIAS, 2006); (iii) capacidade de disseminar o conhecimento gerado; (iv) potencialidade para fundamentar o processo decisório.

A relevância do tema é dada (i) pelo contexto atual das organizações no que tange aos seus objetivos de negócios, que estão cada vez mais buscando a variedade correta de produtos, para o mercado-alvo como ferramenta de vantagem competitiva (JIAO et al, 2004); (ii) pela factibilidade em resolver problemas com a metodologia utilizada nessa pesquisa (BANA; COSTA; ENSSLIN et al, 1999); (iii) pela evolução científica ao criar critérios para a gestão do portfólio de produtos.

Esse artigo se divide em cinco seções, além dessa introdução. Na segunda seção é apresentada a Metodologia de Pesquisa. Na terceira seção se encontra a Fundamentação Teórica da presente pesquisa. Na quarta seção apresentam-se o Estudo de caso realizado para atingir o objetivo de pesquisa. A quinta seção compreende as Considerações Finais. Por fim, é apresentada a seção das referências bibliográficas utilizadas ao longo do texto.

\section{METODOLOGIA DE PESQUISA}

A seção de metodologia da pesquisa está divida em duas seções. A primeira apresenta o enquadramento metodológico da pesquisa, ao passo que a segunda aborda os procedimentos para a construção do modelo multicritério.

\subsection{Enquadramento Metodológico}

Por se tratar de um trabalho com foco em gestão de uma organização fabril, esta pesquisa pode ser caracterizada como aplicada ou tecnológica.

Quanto aos objetivos, pode ser descrita como pesquisa exploratória, o que segundo Gil (2002) apud Bortoluzzi et al, (2009), objetiva proporcionar maior familiaridade com o problema, para torná-lo mais explícito.

Esta pesquisa também se caracteriza como quali-quantitativa. A dimensão qualitativa tem o objetivo de aprofundar o conhecimento sobre o fenômeno, por meio da identificação dos critérios e a construção de escalas em um primeiro momento ordinais que irão compor o modelo ordinal de avaliação. Já a quantitativa, faz uso de modelos matemáticos para converter as escalas ordinais em escalas cardinais e, posteriormente, para identificar taxas de substituição que servirão para integrar os critérios do modelo e permitir uma avaliação de desempenho global (VIANNA; ENSSLIN, 2008). Segundo Ensslin (2002), as pesquisas qualitativas e quantitativas coexistem nos modelos construtivistas como da MCDA-C, uma vez que todo 
conhecimento é inicialmente qualitativo requerendo sua quantificação num segundo momento para agregar conhecimento preferencial quanto à diferença de atratividade entre os níveis inicialmente ordinais (ENSSLIN et al, 2010).

Os procedimentos para coleta de dados desta pesquisa são de origem primária, vez que são obtidas por meio de entrevistas com os decisores. Os dados são utilizados no estudo de caso voltando-se para a gestão de portfólio de produtos.

\subsection{Procedimentos para Construção do Modelo Multicritério}

Devido ao ambiente em estudo se tratar de um contexto complexo, conflituoso e incerto onde o decisor necessita de suporte para identificar, organizar, mensurar e integrar os fatores segundo seus valores e preferências, optou-se pela aplicação da Metodologia Multicritério em Apoio à Decisão Construtivista (MCDA-C) por ser adequar a este tipo de aplicação (ENSSLIN et al, 2010; GRZEBIELUCKAS et al, 2011).

A figura 1 apresenta graficamente a construção do modelo de avaliação de desempenho que é realizada na metodologia MCDA-C em forma sistêmica e sistemática em três fases que facilitam seu entendimento e aplicação: Fase de estruturação (qualitativa), Fase de avaliação (quantitativa), e Fase de recomendações (qualitativa e quantitativa) (BANA; COSTA et al, 1999).

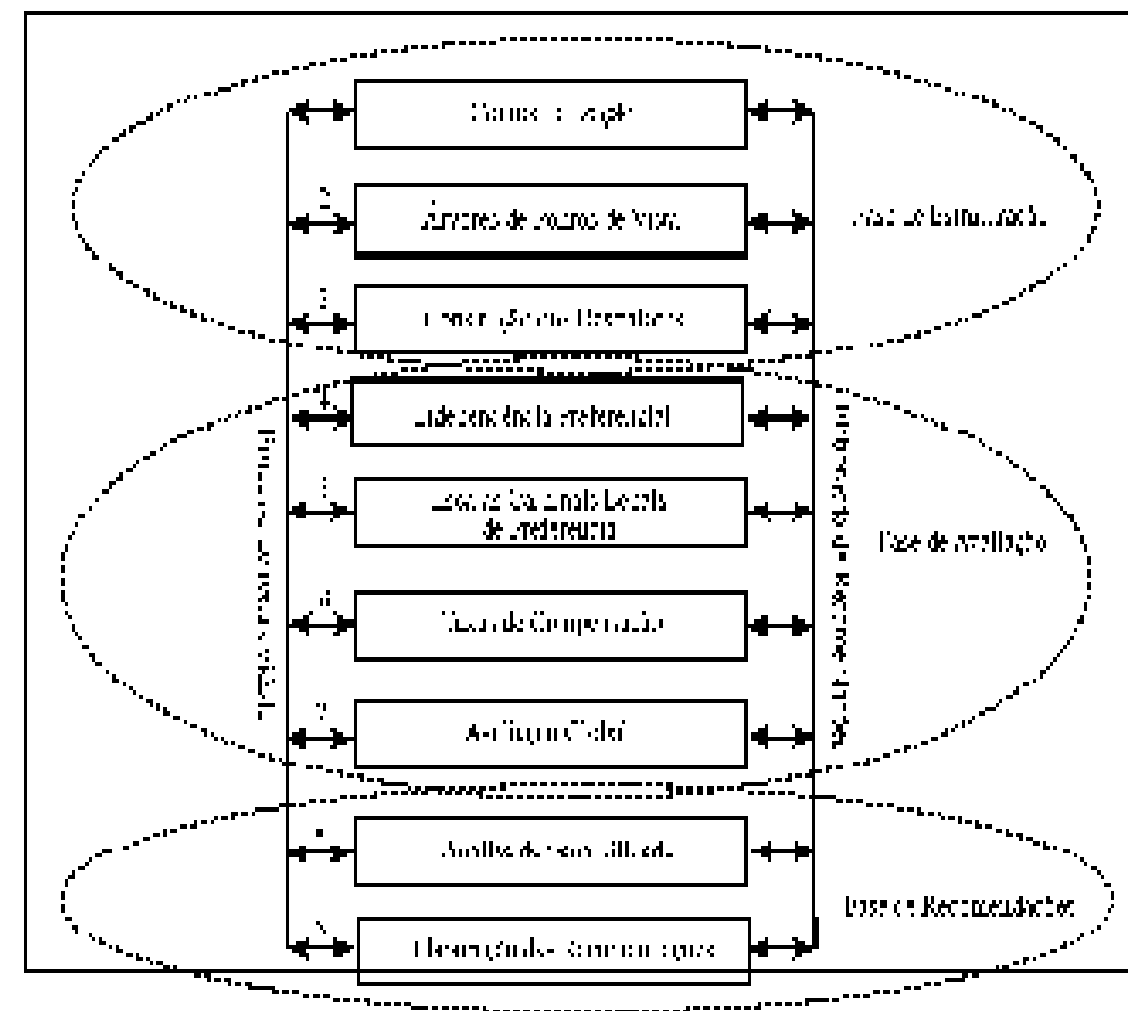

Figura 1 - Fases do MCDA-C. Fonte: Adaptado de Ensslin (2010) 


\subsubsection{Estruturação}

A estruturação é a fase inicial da metodologia e se constitui no fator mais crítico ao sucesso do processo de apoio à decisão, pois visa construir o entendimento do problema e de todo o contexto onde o mesmo está inserido (ENSSLIN; LONGARAY; MACKNESS, 2005; MONTIBELLER; SHAW; WESTCOMBE, 2006). Essa fase contribui para identificar, organizar e mensurar ordinalmente os critérios que representarão os interesses e as preocupações que $o$ decisor considera suficientes e necessárias para a situação decisional. A estruturação se divide usualmente em quatro etapas: Contextualização, Identificação dos Elementos Primários de Avaliação (EPAs), Construção de mapas de relação meio-fim em paralelo com a construção das estruturas hierárquicas de objetivos e construção dos descritores.

A etapa de contextualização aborda o ambiente onde o problema está inserido, quem são os atores envolvidos e quais os objetivos almejados.

Enquanto isso, a segunda etapa da estruturação é realizada por meio de entrevistas abertas onde o decisor é incentivado a mostrar suas preocupações, desejos e objetivos, denominados Elementos Primários de Avaliação (EPAs), que são os fatores essenciais do sistema de valores dos decisores. Ato contínuo é solicitado ao decisor para expandir o entendimento de cada EPA identificando a direção de preferência a ele subjacente assim como o oposto psicológico associado às conseqüências que ele deseja evitar. Cada EPA gera um ou mais conceitos orientados para a ação. A seguir, o decisor é incentivado a agrupar estes conceitos em Áreas de Preocupação.

A terceira etapa consiste na integração hierárquica e sistêmica dos conceitos para transformar os objetivos individuais, representados pelos conceitos, em objetivos fundamentais. Isto é, realizado com a construção de mapas cognitivos para cada área de Preocupação. Nesta etapa é usual que novos conceitos emirjam (ENSSLIN; MONTIBELLER; NORONHA, 2001). Os conjuntos de conceitos com ligações mais fortes entre si são então agregados em clusters. Cada cluster representa uma dimensão de avaliação compostas por candidatos a Pontos de Vista Fundamentais (PVF). Os conceitos geradores de cada candidato a PVF são utilizados para iniciar a construção dos mapas de relação meio-fim (BANA; COSTA et al, 1999; EDEN; JONES; SIMS,1984; ENSSLIN; DUTRA; ENSSLIN, 2000; ENSSLIN et al, 2010), para expandir o entendimento do contexto, segundo a percepção do decisor e identificar quais os aspectos julgados como relevantes. Este processo continua até que se tenha alcançado um grau de entendimento que permita estabelecer o conjunto de percepções que alinhem os objetivos estratégicos representados pelos PVFs do contexto com as propriedades operacionais factuais. De acordo com Keeney (1992), Ensslin, Montibeller \& Noronha (2001) e Roy (2005) os clusters representam um subsistema de preocupações associado ao contexto (sistema). O mapa de relações meio-fim gerado é, então, transformado em uma Estrutura Hierárquica de Valor que representa os pontos de vista do mapa anterior em uma forma explicativa.

Finalizando a fase de estruturação tem-se identificado a cadeia de Pontos de Vista que o decisor considera como necessários e suficientes para avaliar o contexto. Esta cadeia tem seu ápice no Ponto de Vista Fundamental (objetivo estratégico para o contexto) e início em um Ponto de Vista Elementar que estará associado a uma propriedade física do contexto. Este último determina "o que" o 
decisor percebe como necessário medir. Para esta mensuração a metodologia MCDA-C constrói escalas ordinais denominadas descritores ou indicadores de desempenho (BANA; COSTA et al, 1999; ENSSLIN et al, 2010; LACERDA et al, 2011; LACERDA et al, 2011b).

A etapa final da construção do modelo qualitativo ocorre com a definição pelo decisor dos desempenhos por ele considerados como comprometedor, de mercado e excelência em cada descritor. Isto ocorre com o estabelecimento das fronteiras entre estes três campos e são chamados níveis de referência "Bom" e "Neutro" utilizando-se o processo proposto por Bana e Costa et al, (1999). Com os descritores é encerrado o processo de geração de conhecimento qualitativo e, conseqüentemente, a etapa de Estruturação.

\subsubsection{Avaliação}

A MCDA-C é um instrumento para construir conhecimento no decisor (Roy, 1994), de formas a permitir - Ihe com clareza visualizar as conseqüências de suas decisões em seus valores e preferências. A etapa de estruturação construiu o entendimento qualitativo julgado pelo decisor como necessário e suficiente. Para expandir este entendimento torna-se necessário agora transformar este conhecimento, que está materializado em um modelo ordinal, em um modelo cardinal. Para realizar esta transformação a metodologia MCDA-C utiliza modelos compensatórios (Agregação Única de Síntese). Estes modelos requerem que as taxas de compensação sejam constantes. Para alcançar esta condição, os critérios necessitam ser cardinalmente preferencialmente independentes (ENSSLIN et al, 2010).

Uma vez testado a Independência Preferencial Cardinal dos critérios a segunda fase da construção do modelo multicritério denominada de avaliação consiste na incorporação de informações preferenciais dos decisores que permitem transformar as escalas ordinais em cardinais. A avaliação se divide em etapas de: Análise de Independência Preferencial Cardinal; Construção das funções de valor; e Identificação das taxas de substituição.

A função de valor explicita a diferença de atratividade entre os níveis e as Taxas de Substituição, a relação de compensação entre a atratividade dos intervalos de referência dos Pontos de Vista considerados (ENSSLIN; LONGARAY; MACKNESS, 2005; LACERDA et al, 2011a; LACERDA et al, 2011b).

Para Ensslin, Montibeller \& Noronha (2001) as funções de valor são um instrumento para auxiliar os decisores a expressar, em forma numérica, suas preferências. Tendo em vista que as funções de valor a serem construídas, em sua grande maioria, terão o zero arbitrário, as mesmas não poderão ser escalas de razão, mas sim escalas de intervalo e estas para sua definição necessitam a explicitação do zero e a unidade ou equivalentemente de dois pontos (BARZILAI, 2001). Assim a metodologia MCDA-C utiliza como pontos de referência os níveis "Bom" e nível "Neutro". O nível "Bom" corresponde à transição de um desempenho em nível de mercado para excelência. O nível "Neutro" corresponde à transição do nível comprometedor para o de mercado. O nível "Neutro" da escala foi fixado em 0 (zero) pontos e o nível "Bom" em 100 (cem) pontos, fazendo com que os níveis "Bom" e "Neutro" tenham uma representatividade equivalente em termos de significado físico e numérico em todos os critérios de avaliação do modelo. 
$\mathrm{Na}$ segunda etapa da fase de avaliação são identificadas as taxas de substituição, com o objetivo de permitir a avaliação global do modelo. Para isso, realiza-se a ordenação preferencial das alternativas, por meio da matriz de ordenação (ROBERTS, 1979). Quando o decisor preferir a alternativa da linha, marca-se na coluna com a qual está comparando o valor 1 , em caso contrário, zero. Ao final somam-se os valores das linhas e se obtém o grau de preferência conforme o valor da soma. Gera-se, desta forma, a hierarquização das alternativas, cuja ordem reflete a preferência do decisor ao passar do nível "Neutro" para o nível "Bom" em cada PVE. Após esta ordenação, as taxas podem ser calculadas com auxilio do software MACBETH (Measuring Attractiveness by a Categorical Based Evaluation Technique) desenvolvido por Bana e Costa et al, (1999), utilizando-se comparação par a par dos PVEs, permitindo com isso agregar as diversas dimensões de avaliação através de uma função de agregação aditiva na forma de uma soma ponderada.

Os modelos construídos pela metodologia MCDA-C permitem explicitar a avaliação em forma numérica e/ou gráfica. Isto facilita a identificação e compreensão da intensidade dos pontos fortes e fracos das alternativas avaliadas.

\subsubsection{Recomendações}

A terceira fase do projeto é a fase de recomendações, que consiste em mostrar o impacto da situação atual em cada descritor, agora com sua função de valor e, evidenciar os pontos fracos e fortes. A partir deste conhecimento de monitoração podem-se gerar ações para melhorar o desempenho em relação à situação atual. Essas ações são organizadas em estratégias para aperfeiçoamento do desempenho que melhor atenda aos objetivos do decisor. Nessa fase também é possível verificar a estabilidade das opções de escolha do decisor, realizando uma análise de sensibilidade no impacto das alternativas nas escalas, nas diferenças de atratividade das escalas cardinais, e nas taxas de compensação (ENSSLIN; MONTIBELLER; NORONHA, 2001).

É possível verificar que a fase de recomendações evidencia um processo contínuo de expansão do entendimento do contexto ao buscar compreender as conseqüências das possíveis decisões nos critérios representativos das dimensões consideradas relevantes pelo decisor, bem como no contexto como um todo (ENSSLIN; MONTIBELLER; NORONHA, 2001).

\section{FUNDAMENTAÇÃO TEÓRICA}

A Metodologia Multicritério de Apoio a Decisão - Construtivista (MCDA-C) se consolida como instrumento científico somente a partir da década de 1990 com os trabalhos de Keeney (1992), Landry (1995), Roy (1996), Bana e Costa et al, (1999), dentre outros. Segundo Roy \& Vanderpootem (1996), o Apoio à Decisão Construtivista parte do pressuposto de que os processos decisórios são complexos, singulares, e reconhecem os limites da objetividade (o conhecimento existente no início do processo não é suficiente e necessita ser expandido). Para estes ambientes um processo de apoio à decisão, que tenha em conta sua singularidade e 
reconheça que o facilitador em conjunto com o desenvolvimento do modelo necessita expandir o conhecimento do decisor sobre os critérios que este utilizará para representar seus valores e preferências, é um grande diferencial competitivo. Este processo é denominado por Roy (1993) e Landry (1995) de construtivista justificando assim a denominação MCDA-C (ENSSLIN et al, 2010) para diferenciá-la das demais MCDA que restringem ou eliminam esta etapa.

A lógica de pesquisa da MCDA tradicional é a racionalista dedutiva, enquanto que a MCDA-C utiliza uma lógica de pesquisa construtivista mista (indutiva e dedutiva) (ENSSLIN et al, 2011).

A problemática das metodologias MCDA tradicionais é a da escolha da solução ótima dentre alternativas preexistentes, cujos exemplos dessa visão podem ser encontrados em Zambon et al, (2005), Gomes (2005), Campos \& Almeida (2006), Chen, Kilgour \& Hipel (2008). A limitação das metodologias MCDA tradicionais ocorre quando o decisor não tem claro quais critérios ter em conta e como mensurá-los ordinal e cardinalmente. Esta situação, nas MCDA tradicionais, leva os facilitadores a buscar os critérios externamente aos valores e preferências do decisor ou mesmo externamente ao contexto. A MCDA-C reconhece a singularidade do contexto e trabalha conjuntamente com o decisor para construir (e não identificar) os critérios que melhor representem os interesses e as preocupações associados aos valores e preferências do mesmo para o contexto específico (ENSSLIN et al, 2011).

Roy (1993) e Landry (1995) destacam a importância da visão construtivista no processo decisório, pois busca desenvolver o conhecimento através de um processo metodológico e científico. Conforme Ensslin, Montibeller \& Noronha (2001), "cada decisor tem seus valores, objetivos, crenças, relações sociais e de poder, únicos".

Com o intuito de expandir o conhecimento do decisor nos contextos com as características expostas, a MCDA-C utiliza instrumentos de estruturação de informações capazes de permitir a compreensão das conseqüências de decisões nos aspectos considerados pelo decisor como relevantes. Dessa forma, a metodologia MCDA-C é um instrumento recomendado para situações em que o decisor deseja melhorar seu entendimento atuando com consistência, fundamentação, transparência, domínio e propriedade para interagir com todos os atores envolvidos (LACERDA; ENSSLIN; ENSSLIN, 2010).

\section{ESTUDO DE CASO}

Em organizações onde a inovação, em conjunto com a agilidade e flexibilidade, se constituem em fatores competitivos relevantes, a gestão de portfólio de produtos (GPP) impacta diretamente nestes objetivos estratégicos das empresas. Assim a aplicação da metodologia MCDA-C neste estudo de caso faz-se necessária e é justificada pela capacidade de aprofundar os conhecimentos dos envolvidos sobre o assunto em questão: gestão de portfólio de produtos. Essa metodologia também permite identificar quais os pontos mais importantes para os decisores e, desta forma, orienta a atuação em pontos específicos e identifica o que a organização deverá fazer para alcançar níveis de excelência.

$\mathrm{O}$ aprofundamento no estudo resultou na construção segundo os valores e preferências do decisor para o contexto de um modelo de gestão de portfólio de produtos. No entanto, para melhor demonstrar a utilização da metodologia 
empregada, representar-se-á apenas uma das áreas de preocupação do modelo: Marketing. Assim, serão apresentados 12 indicadores, que permitirão despertar para inúmeras oportunidades de inovação.

\subsection{Fase de Estruturação}

Nesta fase todo o problema é estudado e estruturado. São necessárias várias seções de entrevistas com os decisores.

Em relação ao meio externo, a GPP é essencial para que as necessidades dos consumidores sejam atendidas de maneira ágil e com um custo adequado. Ao mesmo tempo, com relação ao meio interno, a GPP deve ter participação na simplificação dos processos para a obtenção de custos competitivos, bem como disponibilizar uma flexibilidade adequada para atender às necessidades dos clientes. Desta forma, as organizações vêem percebendo a importância de integrar tais necessidades de forma mais assertiva, porém, se deparam com a ausência de um processo sistemático para construção de conhecimento que permita entender o que é realmente importante ao mercado, sem aumentar a complexidade na Fábrica, assim como gerar aperfeiçoamentos.

Diante da problemática supracitada e sua considerável abrangência, será construído um modelo de Gestão de Portfólio de Produtos de uma organização que produz produtos da linha branca, como refrigeradores, fogões e lavadoras. A construção do presente modelo foi realizada tendo como decisores o Gerente de Marketing e o Gerente de Tecnologia e como facilitadores os Autores do presente trabalho. Os demais atores envolvidos são os chamados intervenientes - que influenciam os decisores quanto a seus valores: os demais Gerentes de: Manufatura, Qualidade, Suprimentos, Design, Controladoria e Logística. Os atores que são afetados, pelo ambiente e pelas decisões, mas não participam do processo de explicitação dos valores e preferências dos decisores para o contexto são os agidos, neste caso, os demais funcionários da empresa. Assim foi elaborado o quadro 1 no qual são listados os atores envolvidos no contexto do problema.

Tabela 1 - Atores. Fonte: Elaborado pelos autores.

\begin{tabular}{|l|l|}
\hline Atores & Descrição dos atores \\
\hline \multirow{2}{*}{ Decisores } & Gerente de Marketing \\
\cline { 2 - 3 } & Gerente de Tecnologia \\
\hline $\begin{array}{l}\text { Facilitadore } \\
\text { s }\end{array}$ & Os Autores \\
\hline $\begin{array}{l}\text { Intervenient } \\
\text { es }\end{array}$ & $\begin{array}{l}\text { Gerentes de: Manufatura, Qualidade, Suprimentos, Design, } \\
\text { Controladoria e Logística. }\end{array}$ \\
\hline Agidos & $\begin{array}{l}\text { Funcionários da empresa não diretamente ligados aos } \\
\text { decisores }\end{array}$ \\
\hline
\end{tabular}

Logo, ao final do trabalho ter-se-ão os pontos que os decisores consideram em seu processo de avaliação identificados, organizados, mensurados e integrados, permitindo visualizar o quanto cada produto atende suas expectativas.

O rótulo do problema foi definido como: Gestão de Portfólio de Produtos em uma empresa de Eletrodomésticos. Logo nas primeiras reuniões os 
facilitadores solicitaram que os decisores discorressem a respeito do problema e, por meio de suas declarações foram identificadas as características do contexto que impactam seus valores. Neste primeiro momento foram listados 83 EPAs, no quadro 2 estão representados 5 deles.

Tabela 2 - Alguns EPAs identificados. Fonte: Elaborado pelos autores.

\begin{tabular}{|l|l|}
\hline EPA & Descrição \\
\hline 1 & Crescimento de mercado \\
\hline 2 & Concorrentes \\
\hline 3 & Oportunidades de diferenciação dos produtos \\
\hline 4 & Segmentação do mercado \\
\hline 5 & Força da marca em relação à concorrência \\
\hline
\end{tabular}

Após esta etapa, os facilitadores se preocuparam em ampliar o entendimento dos decisores sobre cada EPA, identificando a direção de preferência desejável e de seu oposto psicológico - consequência que os gestores desejam evitar. O quadro 3 apresenta os conceitos formados a partir dos EPAs apresentados no quadro 2. Para entendimento do grau de aceitabilidade das descrições, lê-se o símbolo "..." como "ao invés de" ou "é preferível a". O mesmo trabalho foi realizado com todos os demais EPAs.

Tabela 3 - Alguns Conceitos. Fonte: Elaborado pelos autores.

\begin{tabular}{|l|l|}
\hline $\begin{array}{l}\text { Conceit } \\
\mathbf{0}\end{array}$ & Descrição \\
\hline C1 & $\begin{array}{l}\text { Desenvolver um Portfólio para um mercado em crescimento...não } \\
\text { obter retorno sobre o investimento }\end{array}$ \\
\hline C2 & Ter "portfólio" diversificado... Deixar de atender segmentos do mercado \\
\hline C3 & $\begin{array}{l}\text { O "Portfólio" ganhar da rivalidade dos concorrentes... Perder mercado } \\
\text { para os concorrentes }\end{array}$ \\
\hline C4 & $\begin{array}{l}\text { Possuir força da marca em relação à concorrência... Não possuir uma } \\
\text { marca conhecida }\end{array}$ \\
\hline C5 & $\begin{array}{l}\text { Garantir extensão do mix de produtos... Clientes buscarem nos } \\
\text { concorrentes o que necessitam }\end{array}$ \\
\hline
\end{tabular}

Embasados nos conceitos criados, os decisores foram instigados a refletirem sobre grandes preocupações que explicassem o problema em questão. Um a um os conceitos foram classificados e, sempre que algum conceito não se encaixasse em nenhuma das áreas uma nova área deveria ser criada. É importante e necessário ressaltar que cada área deve ser explicada não pelo nome que recebe, mas sim, pelos conceitos que nela estão contidos. Sendo assim, as primeiras áreas nomeadas foram: Mercado e Empresa.

Ainda seguindo uma análise "top down", área por área, os decisores refletiram sobre subáreas de preocupação, alocando os conceitos da mesma forma que o passo anterior. Desta forma, a figura 2 revela as duas grandes áreas e as oito subáreas de preocupação identificadas e os seus respectivos conceitos. 


\section{Gestão de Portfolio de Produtos}

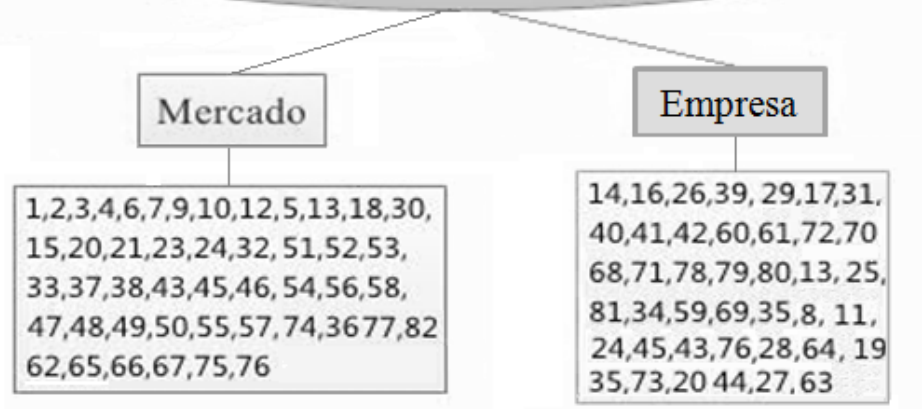

Figura 2 - Áreas de preocupação, subáreas de preocupação e alocação dos conceitos. Fonte:

Elaborado pelos autores.

A partir de então, passa-se a analisar os conceitos no sentido contrário, "bottom up", ampliando o entendimento sobre cada área por meio da construção dos mapas meio-fim. No caso da subárea de preocupação "Marketing" os quatro conceitos nele contidos foram analisados pelos decisores através das seguintes reflexões: "Como eu posso obter esse conceito?" e "Por que esse conceito é importante?". Procurando sempre analisar a suficiência e a necessidade de cada um deles. Por meio deste mapa de raciocínio foram identificados 3 (três) novos conceitos não lembrados anteriormente pelos decisores. No mapa de raciocínio cada conceito-meio deve ser explicado pelos conceitos abaixo dele contidos, formando os chamados "clusters" - grupo de conceitos que explicam uma determinada preocupação. Logo, ao analisar os "clusters" no sentido "bottom up", uma mesma linha de raciocínio será seguida de modo a explicar o rótulo do problema. A figura 3 mostra os sete novos conceitos e os "clusters" identificados dentro da área de preocupação "Marketing" e da subárea "Segmentação". 


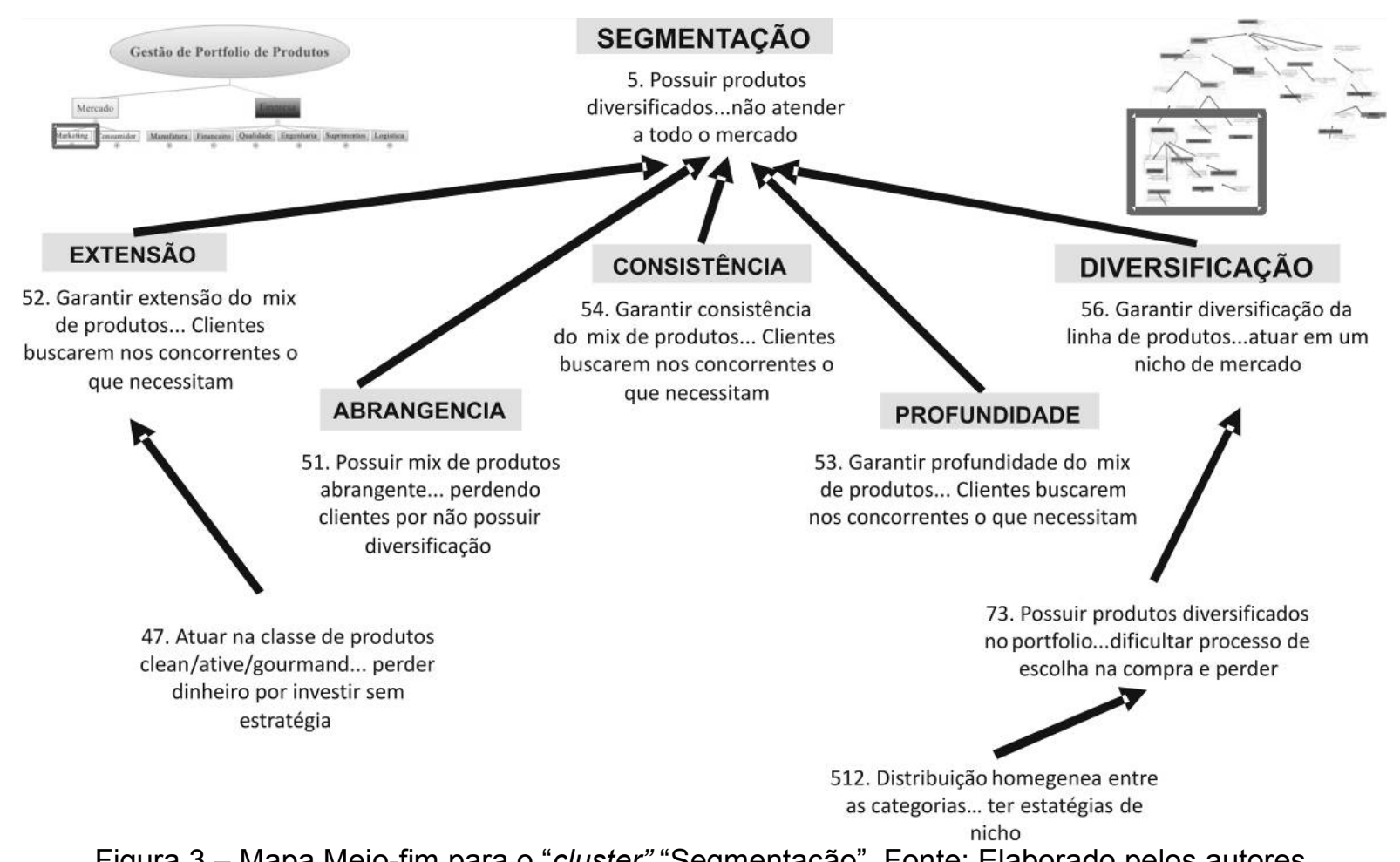

Figura 3 - Mapa Meio-fim para o "cluster” "Segmentação". Fonte: Elaborado pelos autores.

Para aumentar o nível de entendimento sobre o assunto a estrutura de relações de influência acima representada é convertida em uma Estrutura Hierárquica de Valor. Desta forma a cada cluster da Estrutura Hierárquica de Relações Meio-Fim haverá um Ponto de Vista na Estrutura Hierárquica de Valor. Para que estes pontos de vista possam contribuir com o processo de gestão do contexto (sistema) os mesmos devem ser analisados e considerados quanto a serem: essenciais, controláveis, completos, mensuráveis, operacionais, isoláveis, não-redundantes, concisos e compreensíveis. Assim que os clusters e seus correspondentes Pontos de Vista foram testados quanto a esses requisitos e puderam então ser convertidos para a Estrutura Hierárquica de Valor, se tornando um Ponto de Vista Fundamental (PVF), como representado na figura 4.

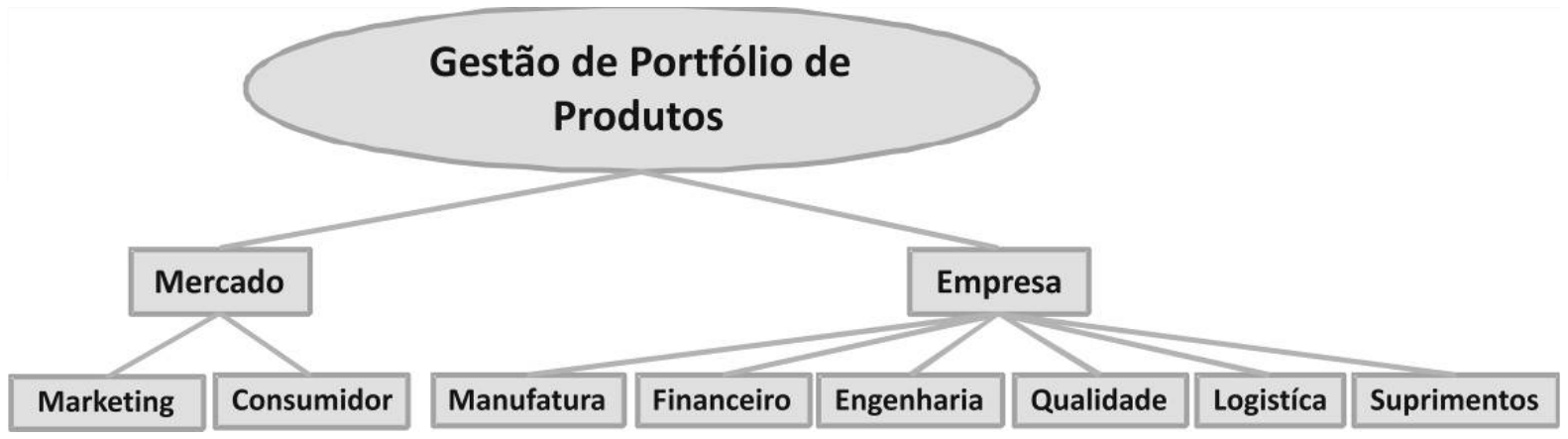

Figura 4 - Estrutura Hierárquica de Valor. Fonte: Elaborado pelos autores.

Da mesma maneira foram analisados os "subclusters" que deram origem aos chamados Pontos de Vista Elementares (PVEs). Repetiu-se o procedimento até chegar a PVEs que representassem o contexto e que, além disso, permitissem a 
mensuração de maneira objetiva e não-ambígua. Concluindo a fase de estruturação do problema, para cada PVE construiu-se uma escala ordinal. Para cada descritor, definiram-se os níveis âncoras "Bom" e "Neutro" e foi identificado o impacto da situação atual.

A figura 5 demonstra a Árvore de Valor criada para a Área de preocupação "Marketing" e os descritores criados para cada PVE.

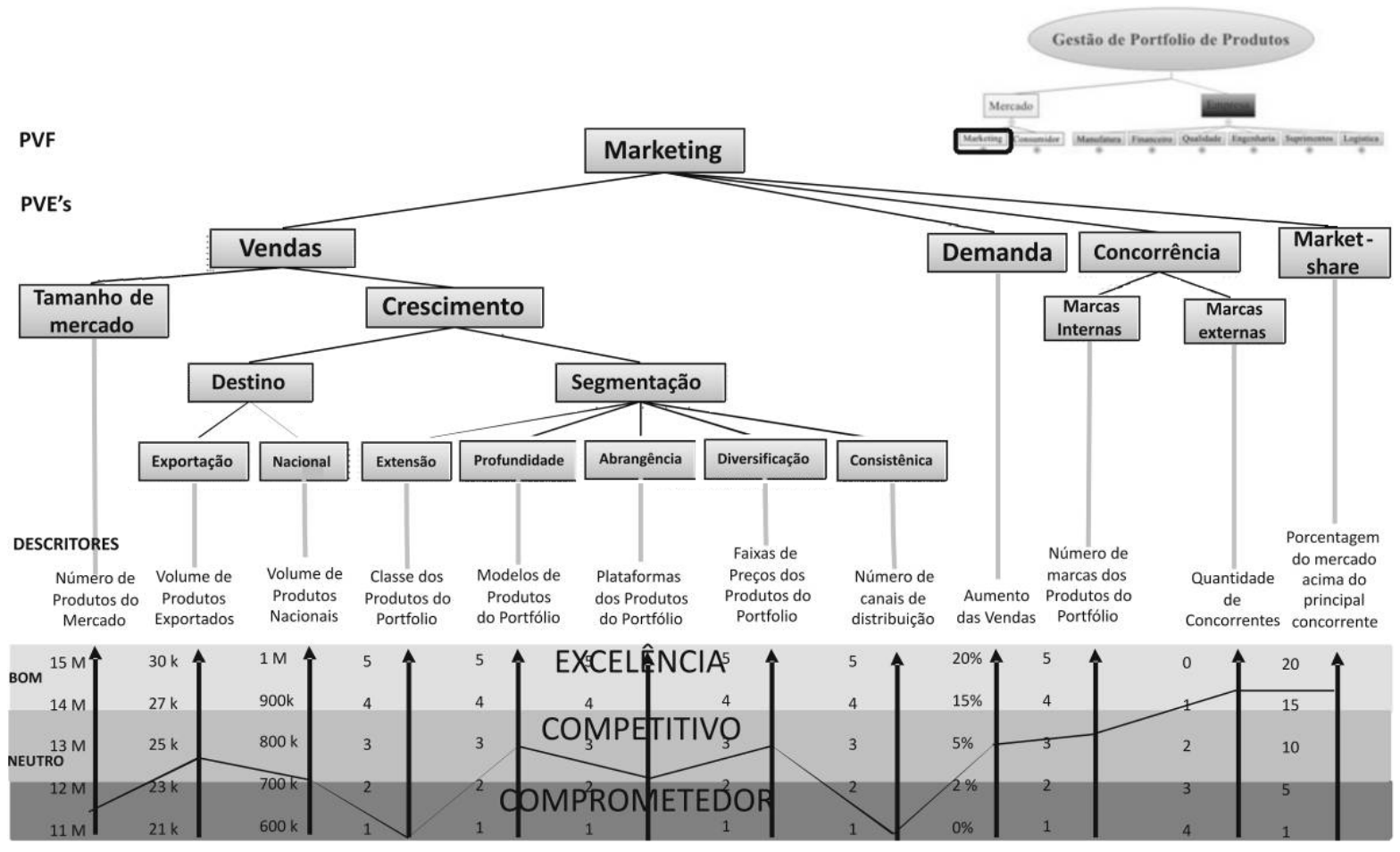

Figura 5 - Árvore hierárquica de valor, PVEs e escalas ordinais do PVF "Marketing". Fonte: Elaborado pelos autores.

O Quadro 4 lista todos os Descritores pertencentes ao PVF "Marketing”. Com isto encerrou-se a Estruturação ou fase qualitativa de construção do modelo.

Tabela 4 - Descritores pertencentes ao PVF "Marketing”. Fonte: Elaborado pelos autores.

\begin{tabular}{|l|l|l|}
\hline PVF & Descritor & ID \\
\hline Marketing & Número de Produtos do Mercado & 1 \\
\hline Marketing & Volume de Produtos Exportados & 2 \\
\hline Marketing & Volume de Produtos Nacionais & 3 \\
\hline Marketing & Classe dos Produtos do Portfólio & 4 \\
\hline Marketing & Modelos de Produtos do Portfólio & 5 \\
\hline Marketing & Plataformas dos Produtos do Portfólio & 6 \\
\hline Marketing & Faixas de Preços dos Produtos do Portfólio & 7 \\
\hline Marketing & Número de canais de distribuição & 8 \\
\hline Marketing & Aumento das Vendas & 9 \\
\hline Marketing & Número de marcas dos Produtos do Portfólio & 10 \\
\hline
\end{tabular}




\begin{tabular}{|l|l|l|}
\hline Marketing & Quantidade de Concorrentes & 11 \\
\hline Marketing & Porcentagem do mercado acima do principal concorrente & 12 \\
\hline
\end{tabular}

A fase seguinte de Avaliação onde cada Descritor será convertido em uma escala de intervalos e, após as escalas, serão agregados valendo-se da diferença de atratividade entre os níveis de referencia em cada função de valor será apresentada a seguir.

\subsection{Fase de Avaliação}

A segunda fase da construção do modelo multicritério é a fase de avaliação que consiste na incorporação de informações preferenciais dos decisores que permitam transformar as escalas ordinais em cardinais. A avaliação se divide nas etapas de: Construção das funções de valor e Identificação das taxas de substituição.

\subsubsection{Funções de Valor}

Para construção das Funções de Valor opta-se por utilizar o software MACBETH (Measuring Attractiveness by Categorical Based Evaluation Technique), por ser dentre os métodos existentes aquele que representa com fundamentação científica todas as diferenças de atratividade das escalas ordinais para transformálas em escalas cardinais. As Funções de Valor serão escalas de intervalo onde os níveis "Bom" e "Neutro" receberão as pontuações 100 e 0, respectivamente. A seguir o decisor é convidado a expressar para todas as combinações dos níveis da escala ordinal a diferença de atratividade entre elas. Com tal propósito o método Macbeth vale-se de uma escala semântica de sete níveis: Extrema, Muito Forte, Forte, Moderada, Fraca, Muito Fraca e Nula.

A figura 8 apresenta o processo completo de transformação de um descritor (escala ordinal) em uma Função de Valor (escala cardinal): o descritor "Marcas Externas"; a Matriz de Julgamento; a Função de Valor, numérica e gráfica. 


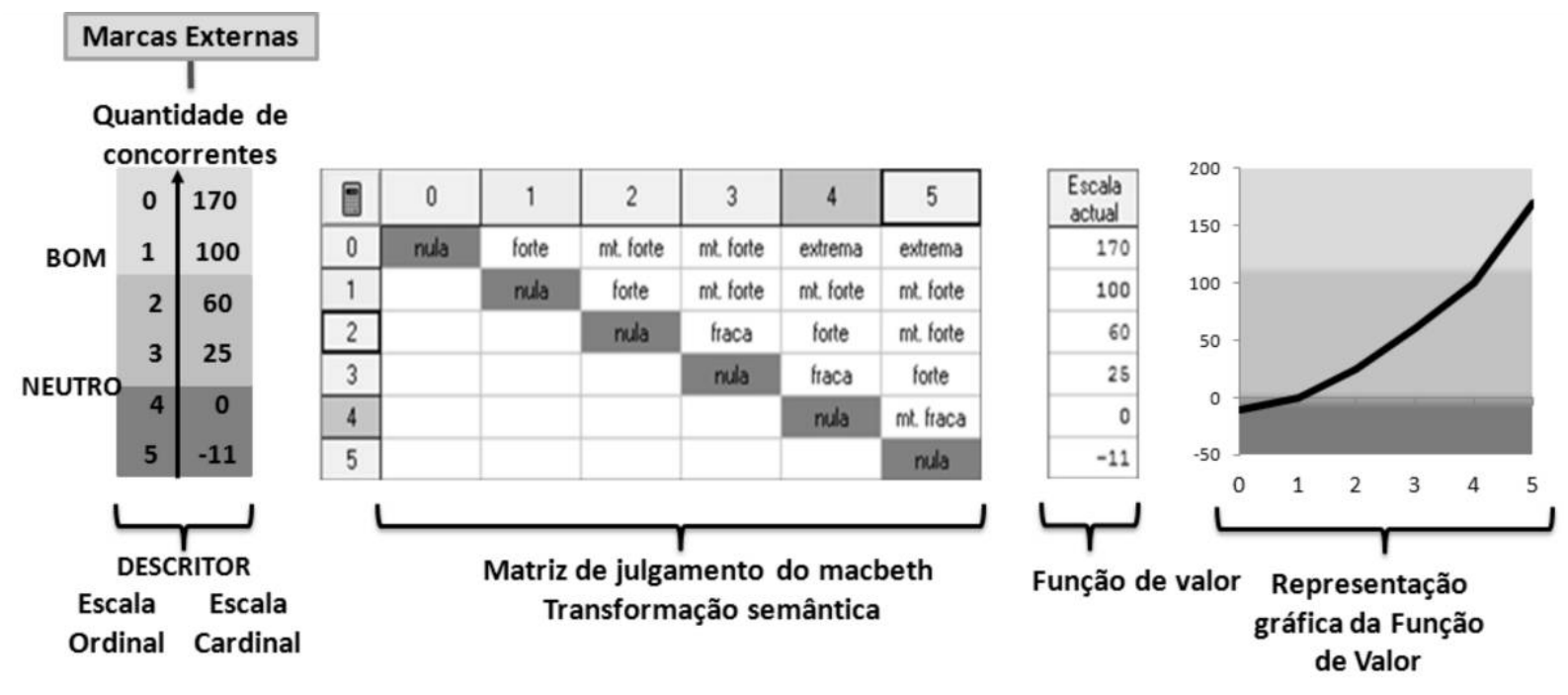

Figura 8 - Transformação do Descritor "Marcas Externas" em Função de Valor por meio do MACBETH. Fonte: Elaborado pelos autores.

Esse procedimento foi realizado para todos os descritores. A figura 9 apresenta o conjunto de escalas cardinais construídas para o PVF "Marketing".

Nesta etapa do processo obtém-se a mensuração cardinal individual de cada aspecto operacional considerado importante pelo decisor. Porém, ainda não é possível avaliar o desempenho em níveis táticos, através dos Pontos de Vista Elementares, e nem dos aspectos julgados estratégicos, através dos Pontos de Vista Fundamentais. Para realizar esta avaliação global é necessário realizar o processo de integração de todos os pontos de vistas, segundo a percepção dos decisores, aplicando-se taxas de substituição (SILVEIRA, 2007), que serão apresentadas na próxima seção.

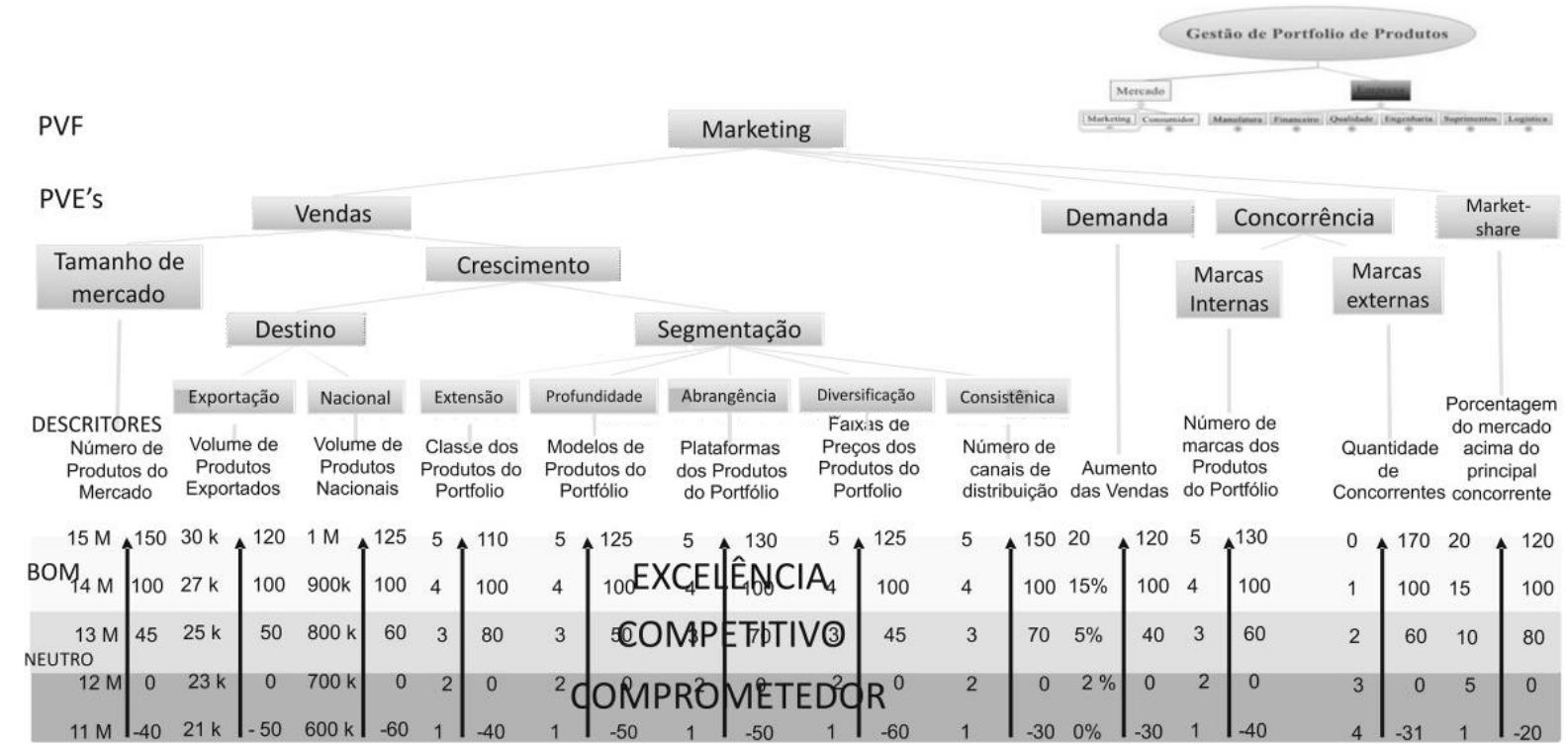

Figura 9 - Escalas cardinais do PVF "Marketing". Fonte: Elaborado pelos autores. 


\subsubsection{Taxas de Substituição}

A figura 10 identifica a estrutura hierárquica abaixo do PVF "Marketing", que exemplificará a integração por meio da definição das taxas (W1, W2, W3, W4 e W5), que representam o juízo de valor preferencial do decisor.

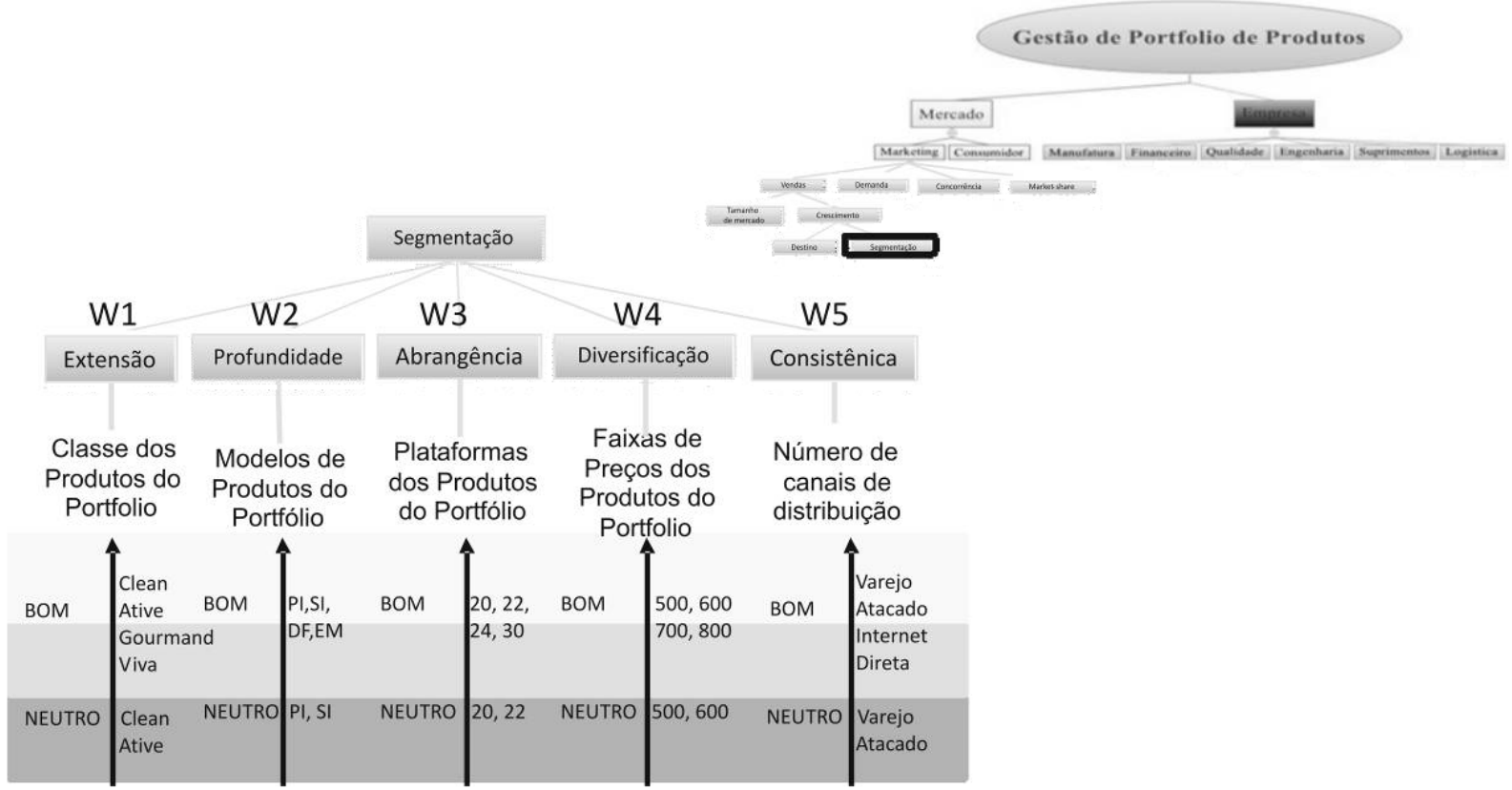

Figura 10 - Estrutura Hierárquica de Valor com destaque para os Descritores do PVE "Segmentação". Fonte: Elaborado pelos autores.

O processo utilizado pela metodologia MCDA-C para determinar as taxas de compensação é realizado em três etapas: geração das alternativas, ordenação das alternativas e construção da matriz de julgamento.

Para a primeira etapa criam-se as alternativas potenciais (A0, A1, A2, A3 e A4 e A5) que representem a contribuição da passagem do nível "Neutro" para o nível "Bom" em cada um dos critérios que se deseja determinar as taxas, assim como uma ação de referência com desempenho "Neutro" em todos os pontos de vista, conforme apresentado na figura 11. 

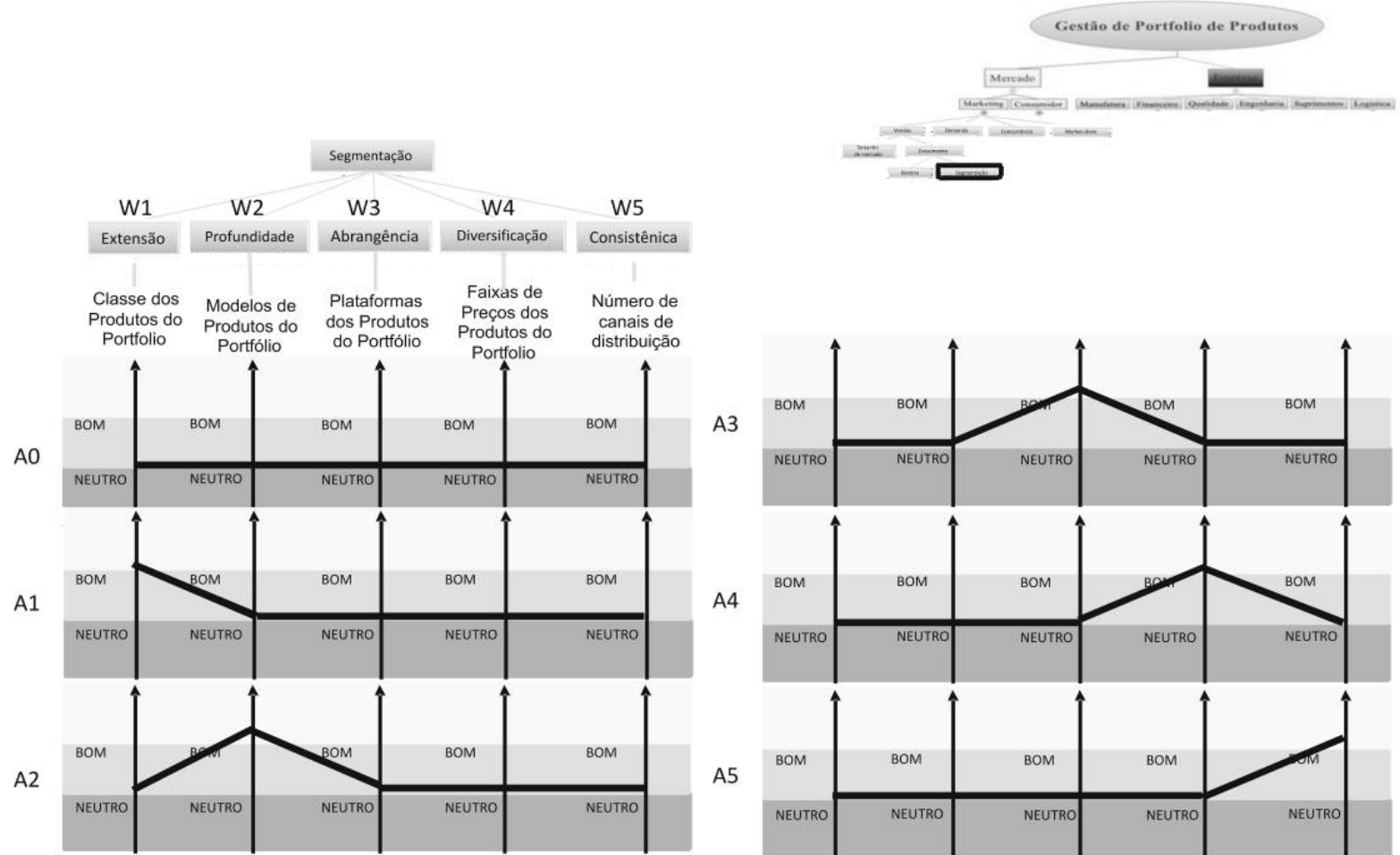

Figura 11 - Alternativas potenciais para determinar as taxas de substituição Fonte: Elaborado pelos autores.

Em seguida, realiza-se uma ordenação preferencial das alternativas, por meio da matriz de ordenação, conforme demonstrado no Quadro 5. Gera-se, desta forma, a hierarquização das alternativas, cuja ordem reflete a preferência do decisor ao passar do nível "Neutro" para o nível "Bom" em cada PVE.

Tabela 5 - Matriz de Roberts da comparação das alternativas do PVE "Segmentação". Fonte: Elaborado pelos autores.

\begin{tabular}{|l|l|l|l|l|l|l|l|}
\hline & A1 & A2 & A3 & A4 & A5 & Soma & Ordem \\
\hline A1 & X & 1 & 0 & 1 & 1 & 3 & $2^{0}$ \\
\hline A2 & 0 & $X$ & 0 & 1 & 1 & 2 & $3^{0}$ \\
\hline A3 & 1 & 1 & $X$ & 1 & 1 & 4 & $1^{0}$ \\
\hline A4 & 0 & 0 & 0 & $X$ & 1 & 1 & $4^{0}$ \\
\hline A5 & 0 & 0 & 0 & 0 & X & 0 & $5^{0}$ \\
\hline
\end{tabular}

$\mathrm{Na}$ seqüência, utilizando a comparação par a par, através do software MACBETH, é solicitado ao decisor que julgasse semanticamente a diferença de atratividade quando se troca de uma alternativa para outra, como pode ser observado na figura 12. As categorias semânticas utilizadas são as mesmas empregadas para obter as Funções de Valor. 


\begin{tabular}{|c|c|c|c|c|c|c|c|c|}
\hline \multicolumn{9}{|c|}{ Whă Ponderação (Global) } \\
\hline 圈 & {$[\mathrm{A} 3]$} & [A1] & {$[\mathrm{A} 2 \mathrm{2}]$} & {$[\mathrm{A} 4$ ] } & {$[A 5]$} & [ tudo inf. ] & $\begin{array}{c}\text { Escala } \\
\text { atual }\end{array}$ & extrema \\
\hline [A3] & nula & moderada & moderada & moderada & forte & extrema & 30.00 & mt. forte \\
\hline [A1] & & nula & nula & nula & moderada & forte & 20.00 & forte \\
\hline [A2] & & nula & nula & nula & moderada & forte & 20.00 & moderada \\
\hline [A4] & & nula & nula & nula & moderada & forte & 20.00 & $\begin{array}{l}\text { firaca } \\
\text { mt. fraca }\end{array}$ \\
\hline [A5] & & & & & nula & moderada & 10.00 & nula \\
\hline [ tudo inf. ] & & & & & & nula & 0.00 & \\
\hline \multicolumn{9}{|c|}{ Julgamentos consistentes } \\
\hline & Q & †영 & $54=5$ & & & ? 算 & & \\
\hline
\end{tabular}

Figura 12 - Taxas de substituição calculadas pelo M-Macbeth para as alternativas do PVE "Segmentação". Fonte: MACBETH adaptado para o estudo de caso (2011).

Este processo é realizado para todos os demais $\mathrm{PVs}$ da estrutura hierárquica. A figura 13 ilustra a Estrutura Hierárquica de Valor com as Taxas de Substituição do modelo construído, para os Pontos de Vista do cluster "Marketing".

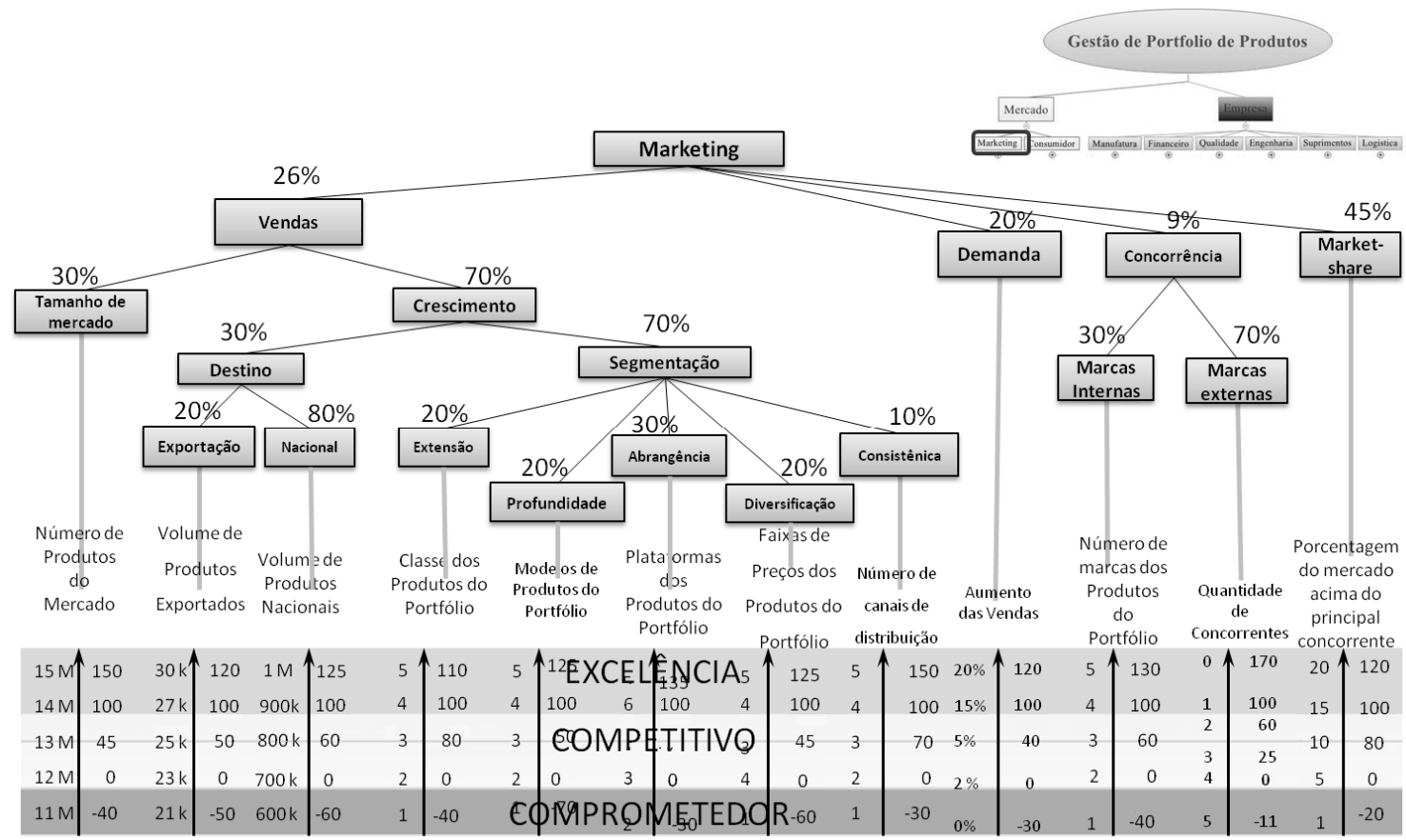

Figura 13 - Estrutura Hierárquica de Valor com as Taxas de Substituição. Fonte: Elaborado pelos autores.

De posse então das Funções de Valor e das Taxas de substituição é possível deduzir a equação global de avaliação do modelo, que será vista na próxima seção.

\subsubsection{Avaliação Global e Perfil de Impacto da Situação Atual}

O impacto de uma ação "a" em um PVF na avaliação global é obtido através do somatório da pontuação multiplicada pela taxa de substituição correspondente de cada critério deste PVF, por meio da equação (1). 


$$
\mathrm{V}(\mathrm{a})=\sum_{i=1} w_{\mathrm{i}} \mathrm{X} v_{\mathrm{i}}(\mathrm{a})
$$

Em que:

$V(a)=$ valor do Desempenho econômico-financeiro Global;

$v_{1}(a), v_{2}(a), \ldots v_{n}(a)=$ valor parcial do desempenho econômico-financeiro nos critérios $1,2, . \mathrm{n}$;

$\mathrm{w}_{1}, \mathrm{w}_{2}, \ldots \mathrm{w}_{\mathrm{n}}=$ taxas de substituição nos critérios $1,2, \ldots \mathrm{n}$;

$\mathrm{n}=\mathrm{n}^{\circ}$ de critérios do modelo;

Para o $\mathrm{PVF}_{1}$ ilustrado na figura 11 , ter-se-ia a equação (2):

$$
\begin{aligned}
& \mathrm{V}_{\text {PVF1 }}=0,26\left\{0,30^{*} \mathrm{~V}_{\text {Mercado }}(a)+0,70^{*}\left(0,30^{*}\left(0,20^{*} \mathrm{~V}_{\text {Exp }}(a)+\right.\right.\right. \\
& \left.0,80^{*} \mathrm{~V}_{\text {Nac }}(a)\right)+0,70^{*}\left(0,20^{*} \mathrm{~V}_{\text {Ext }}(a)+0,20^{*} \mathrm{~V}_{\text {Prof }}(a)+0,30^{*} \mathrm{~V}_{\text {Abrag }}(a)\right)+ \\
& \left.0,20^{*} \mathrm{~V}_{\text {Divers }}(a)+0,10^{*} \mathrm{~V}_{\text {Cons }}(a)\right)+0,20^{*} \mathrm{~V}_{\text {Demanda }}(a)+0,09^{*}\left(0,30^{*} \mathrm{~V}_{\text {Mint }}(a)\right. \\
& \left.\left.+0,70^{*} \mathrm{~V}_{\text {MExt }}(a)\right)+0,45^{*} \mathrm{~V}_{\text {Mshare }}(a)\right\}
\end{aligned}
$$

Aplicando-se o mesmo principio para as Áreas de preocupação, ter-se-á a equação (3) representando o impacto no modelo global de uma ação para o PVF 1 "Marketing":

$$
\mathrm{V}(\mathrm{a})=0,26^{*} \mathrm{~V}_{P V E 1}(a)+0,20^{*} \mathrm{~V}_{\mathrm{PVE2}}(\mathrm{a})+0,09^{*} \mathrm{~V}_{\mathrm{PVE} 3}(\mathrm{a})+0,45^{*} \mathrm{~V}_{\mathrm{PVE} 4}(\mathrm{a})
$$

Após aplicar este processo para todas as áreas de preocupação, obtém-se o modelo global da análise multicritério para a gestão do portfólio de produtos. Nesta etapa pode-se traçar o Perfil de Impacto do status quo, que permite identificar onde estão os pontos fortes de cada avaliação e em quais PVEs residem as principais oportunidades de melhoria, como ilustra a figura 14. 


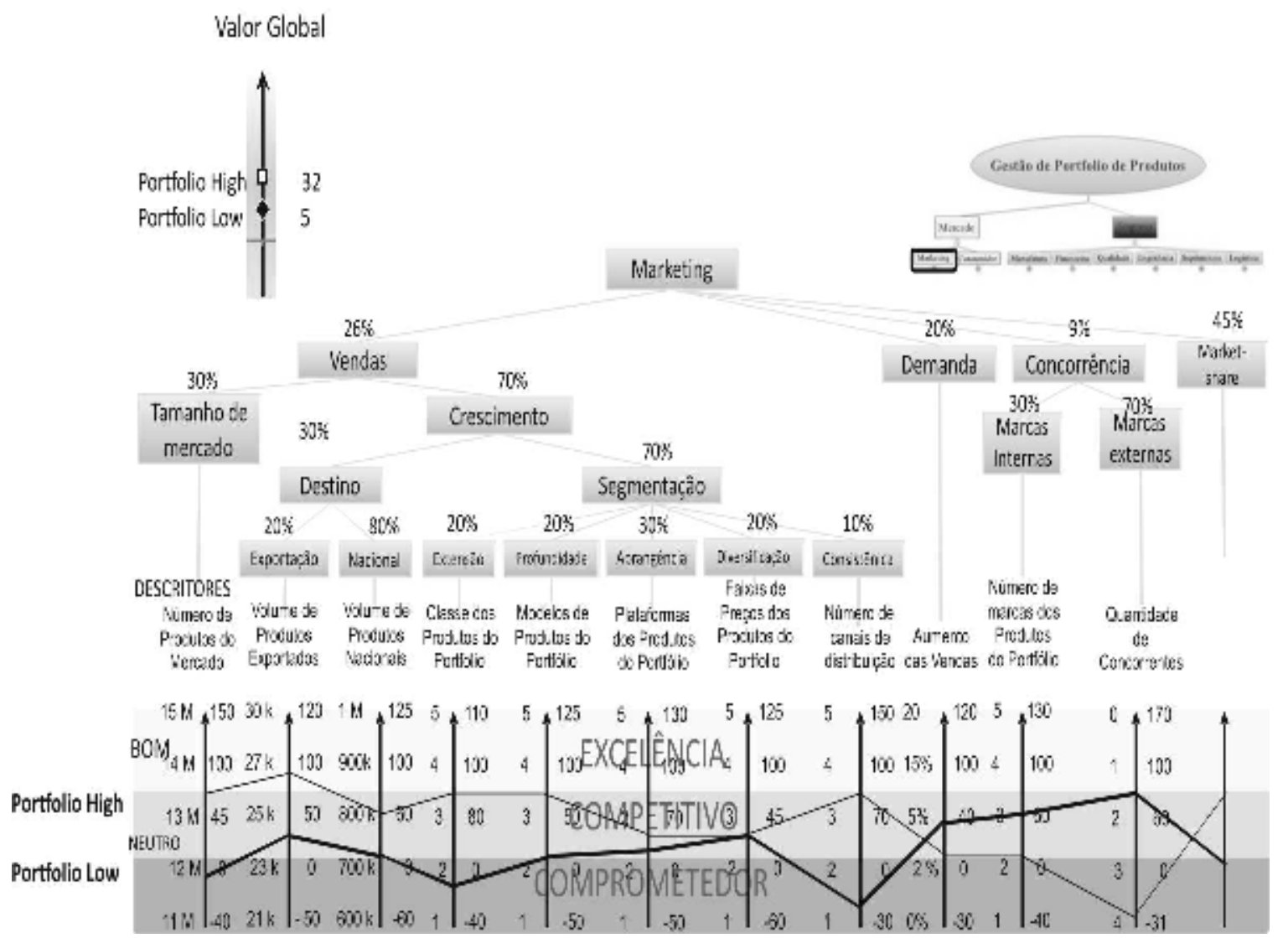

Figura 14 - Perfil de Impacto de dois Portfólios avaliados.

Fonte: Elaborado pelos autores.

O modelo, ao ser construído segundo os valores e preferências do decisor, permite visualizar o desempenho comparativo entre os dois Portfólios, denominando o status quo como Portfólio LOW, com 5 pontos, e uma nova alternativa de Portfólio HIGH, com 32 pontos. Este entendimento ajuda a identificar os locais específicos onde atuar.

O próximo passo consiste de um exame da robustez das respostas do modelo frente as alterações nos parâmetros do mesmo, denominando-se de Análise de sensibilidade.

\subsection{Análise de Sensibilidade}

A Análise de Sensibilidade consiste em verificar a resposta do modelo quando da alteração de seus parâmetros, em especial nas taxas de substituição ou na performance das ações potenciais. A comparação de alternativas com base em suas performances, tanto locais quanto globais, foi realizada com o auxílio do software HIVIEW.

Considerando o critério "Demanda", ilustrado na figura 15, que possui a taxa de substituição de $9 \%$, a alternativa Portfólio LOW somente será superior a alternativa Portfólio HIGH se a taxa de substituição for igual ou maior que $65 \%$. Questionando o decisor, o mesmo considerou as alternativas robustas em relação a 
esta situação, uma vez que este critério dificilmente aumente tanto assim sua taxa de substituição.

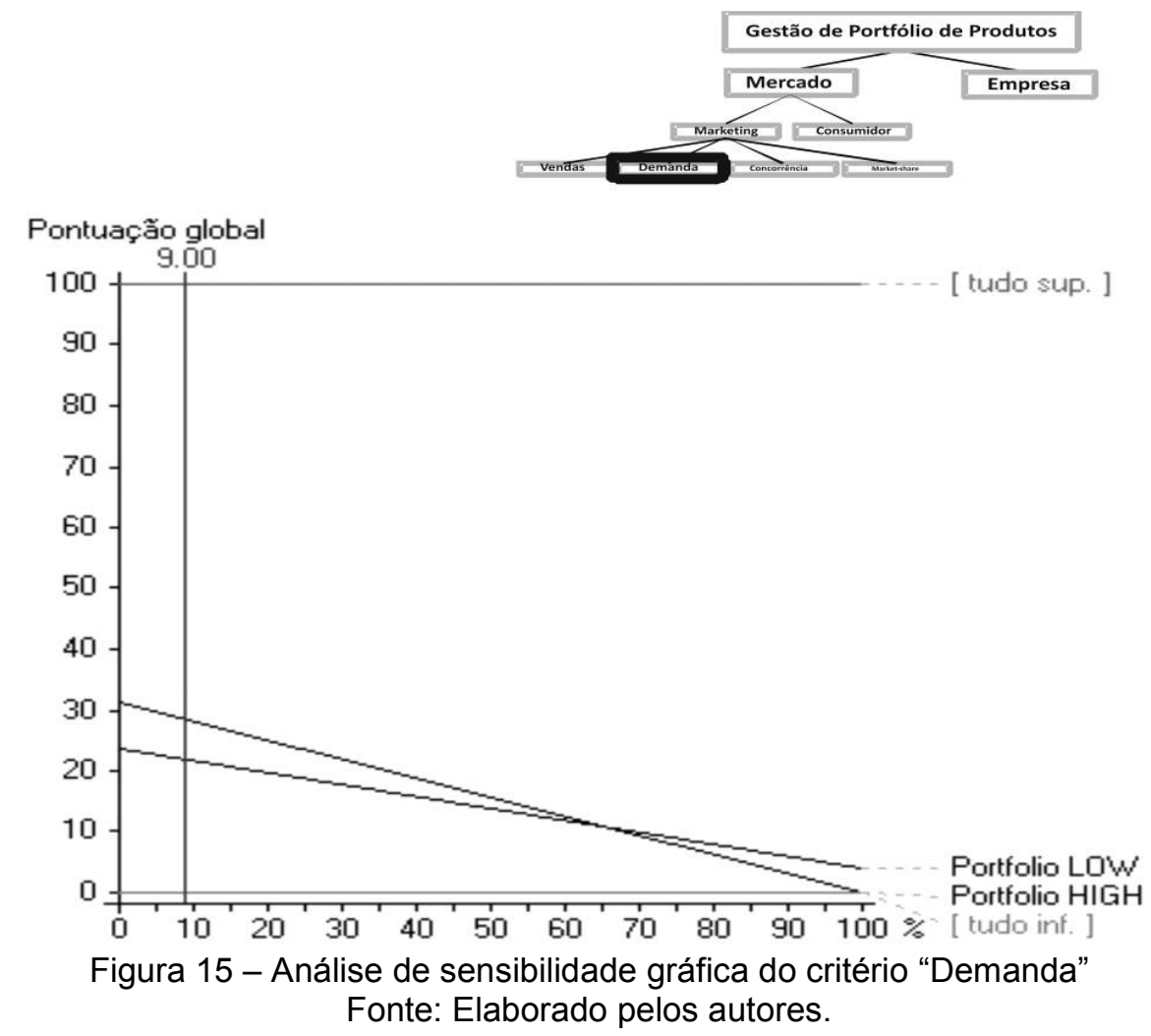

Esse tipo de interpretação é importante para que o decisor possa melhor compreender os critérios atribuídos por ele ao modelo e a robustez das respostas, fatores que irão influenciar sensivelmente na tomada de decisão.

Agora, a empresa necessita identificar ações e avaliar o impacto das mesmas para o alcance dos objetivos estratégicos. Na metodologia MCDA-C esta etapa é denominada Recomendações.

\subsection{Fase de Recomendações}

A metodologia MCDA-C apresenta destaque na etapa de recomendações. Diferencia-se das demais metodologias para avaliação de desempenho por ser capaz de identificar de forma explícita o que é importante e quantificar de forma cardinal os aspectos julgados relevantes pelo decisor, apresentando um processo para evidenciar e quantificar alternativas de melhoria.

O processo de aperfeiçoamento só é possível tendo em vista a metodologia MCDA-C ter construído na etapa de Estruturação os descritores. Este diferencial contém em forma ordenada e quantifica os possíveis desempenhos da propriedade física sendo avaliada, assim quando a situação atual estiver em um dado nível o descritor mostrará qual performance promoverá uma melhoria. Sabe-se onde se está e sabe-se onde se deseja ir. A partir deste conhecimento o decisor tem um 
processo de aperfeiçoamento em cada descritor assim como a quantificação potencial da alternativa.

Inicialmente busca-se identificar nos PVFs onde se deseja aperfeiçoar o desempenho, entretanto, tendo em vista existirem incontáveis oportunidades de melhorias para os dois Portfólios de Produtos analisados na empresa Multinacional de Eletrodomésticos, tornou-se necessário adotar um processo de priorização para que os resultados pudessem ser mais eficientes e eficazes. Destarte, decidiu-se seguir as seguintes etapas: Fórum de debate em nível estratégico para priorização, Oportunidade nos descritores, Oportunidades nos recursos existentes e Identificação das ações mais convenientes.

\subsubsection{Fórum de debate em nível estratégico para priorização}

Com um representante de cada área da empresa em nível estratégico, apresentou-se o resultado da avaliação dos dois Portfólios de Produtos, o LOW e o $H I G H$, os quais apresentaram pontuações globais de 5 e 32 respectivamente. Após análise dos PVFs de cada modelo, assim como sua influência no desempenho global, ficou clara uma lacuna expressiva para melhorias do Portfólio LOW.

\subsubsection{Oportunidade nos descritores}

Com base nas informações levantadas, decide-se focar no aperfeiçoamento do resultado global do Portfólio LOW e estabelecendo como plano de aperfeiçoamento, elevar seus descritores, com desempenho inferior ao da alternativa Portfólio $H I G H$, dos níveis atuais ao nível do Portfólio $\mathrm{HIGH}$ devido ao fato do sucesso comprovado pelo grupo e plano estratégico da empresa.

No quadro 6 são apresentados os cinco primeiros descritores com seus respectivos impactos globais do Portfólio LOW ao passar seus descritores dos seus níveis atuais para os níveis do Portfólio HIGH. Assim foi possível identificar os descritores que tinham maior impacto.

Tabela 6 - Impacto no resultado global dos cinco primeiros descritores.

Fonte: Elaborado pelos autores.

\begin{tabular}{|l|l|l|}
\hline ID & Descritor & Impacto Global \\
\hline 12 & Porcentagem do mercado acima do principal concorrente & 23 pontos \\
\hline 1 & Número de Produtos do Mercado & 5 pontos \\
\hline 4 & Classe dos Produtos do Portfólio & 2 pontos \\
\hline 3 & Volume de Produtos Nacionais & 2 pontos \\
\hline 5 & Modelos de Produtos do Portfólio & 1 pontos \\
\hline
\end{tabular}

Ao consolidar os dados é possível verificar que ao passar todos os descritores do Portfólio LOW ao nível do Portfólio $H I G H$, seria possível identificar um aperfeiçoamento total de 34 pontos no impacto global do modelo de Gestão de Portfólio de Produtos. Desse total de pontos, ficou evidenciado no quadro 6 também 
que apenas 2 descritores (Porcentagem do mercado acima do principal concorrente e Número de Produtos do Mercado) contribuem com 28 pontos, ou seja, ter-se-ia aproximadamente $17 \%$ dos descritores impactando em $80 \%$ do resultado global.

\subsubsection{Oportunidades nos recursos existentes}

Nesta etapa, resolve-se considerar os recursos da empresa com relação às oportunidades de melhoria frente à área de preocupação "Mercado". Novamente com o grupo estratégico reunido, representantes de todas as áreas elaboraram um mapa com o intuito de identificar todos os recursos necessários para os aperfeiçoamentos desejáveis. Com base nesses apontamentos, o grupo verificou que o Descritor 5 - "Modelos de Produtos do Portfólio", apresenta a melhor relação custo $\mathrm{x}$ benefício no impacto global do modelo, além do fato de estar alinhado com o planejamento estratégico da empresa, que consiste na incorporação de novos produtos OEM ao Portfólio LOW, ou seja, produtos acabados comprados de fornecedores da base, tendo como Impactos relacionados as diferentes áreas da empresa, como descrito do no quadro 7.

Tabela 7 - Impactos das alterações no Descritor "Modelos de Produtos do Portfólio". Fonte: Elaborado pelos autores.

\begin{tabular}{|l|l|}
\hline Área & Observações relacionadas \\
\hline Engenheiros & $\begin{array}{l}\text { Apenas atividades de certificação dos novos produtos OEM } \\
\text { incorporados, sem necessidade de atividades de } \\
\text { desenvolvimento; }\end{array}$ \\
\hline Projetistas & $\begin{array}{l}\text { A carga de trabalho dedicada ao desenvolvimento de novos } \\
\text { itens é baixa, devido ao fato de os novos produtos } \\
\text { incorporados serem OEM; }\end{array}$ \\
\hline $\begin{array}{l}\text { Líder } \\
\text { projeto }\end{array}$ & $\begin{array}{l}\text { O tempo estimado para o lançamento de um novo produto } \\
\text { pode variar de 1 a 2 anos. Para o caso de produtos OEM o } \\
\text { prazo estimado reduz para } 6 \text { meses }\end{array}$ \\
\hline Manufatura & $\begin{array}{l}\text { Área não impactada uma vez que os produtos chegam } \\
\text { prontos a empresa; }\end{array}$ \\
\hline Marketing & $\begin{array}{l}\text { Produtos importados são historicamente bem aceitos pelos } \\
\text { consumidores, normalmente resultando em aumento do } \\
\text { número de vendas ou margem de lucro }\end{array}$ \\
\hline $\begin{array}{l}\text { Nível } \\
\text { Estratégico }\end{array}$ & $\begin{array}{l}\text { A incorporação de novos produtos ao Portfólio está alinhada } \\
\text { com a estratégia da empresa na diversificação de seu } \\
\text { campo de atuação; }\end{array}$ \\
\hline Qualidade & $\begin{array}{l}\text { Dados históricos dos Produtos OEM incorporados o Portfólio } \\
\text { indicam um alto índice de satisfação dos consumidores; }\end{array}$ \\
\hline
\end{tabular}

\section{CONSIDERAÇÕES FINAIS}

O objetivo do presente trabalho consiste em construir um modelo de apoio à decisão que evidencie o impacto das decisões nos fatores percebidos pelos 
gestores como necessários e suficientes para avaliar a gestão do portfólio de produtos (GPP) da organização. O instrumento de pesquisa para alcançar este objetivo foi apresentado na seção 2.2 Procedimentos para Construção do Modelo Multicritério, e sua operacionalização foi desenvolvida na seção 4 . Estudo de caso.

Como contribuições geradas pelo trabalho identificam-se na área de Marketing 12 Pontos de Vista Elementares e suas escalas ordinais e cardinais, suas taxas de integração que foram considerados pelos dois gestores como necessários e suficientes para avaliar a área. O conhecimento construído permitiu ainda visualizar gráfica e numericamente, na figura 14, as conseqüências da situação atual e da alternativa proposta, propiciando um processo para gerar ações de melhoria.

Além disto, destaca-se: no nível teórico, a evidenciação das diferenças entre a MCDA-C e a MCDA; no nível prático, a demonstração da potencialidade da metodologia MCDA-C para, em contextos onde o decisor não consegue explicitar o que leva em conta para decidir, construir, a partir da sua participação comprometida, os critérios que ele julga necessários e suficientes para avaliar o contexto.

O modelo construído no Estudo de Caso é legitimado pelo decisor em cada etapa de sua construção, e com sua utilização, tanto o decisor quanto a empresa passaram a contar com um instrumento que permite evidenciar o que é importante, com suas escalas de mensuração e integração e oportuniza a melhoria contínua do seu Portfólio de Produtos, aberto a ações de aperfeiçoamento de formas inovadoras e mais assertivas.

Como limitação da presente pesquisa, pode-se citar que a metodologia proposta (MCDA-C) requer a participação do decisor em todo o processo. Isto decorre em razão do foco do processo de trabalho estar centrado no desenvolvimento do entendimento do decisor.

Por fim, outro ponto a ser ressaltado está relacionado ao caráter de personalização do estudo, não recomendando a aplicação do modelo em outros contextos, uma vez que o modelo é singular, ou seja, é construído segundo os valores e preferências de um decisor específico, em uma organização com características peculiares.

\section{REFERÊNCIAS}

AGARD, B.; KUSIAK, A. Data-mining-based methodology for the design of product families. International Journal of Production Research, v. 42(15), p. 2955-2969, 2004.

BANA E COSTA, C. A.; ENSSLIN, L.; CORREA, E. C.; VANSNICK, J. C. Decision Support Systems in action: Integrated application in a multicriteria decision aid process. European Journal of Operational Research, v. 113, p. 315-335, 1999.

BARZILAI, J. On the Foundations of Measurement. Proceedings of the 2001 IEEE International Conference on Systems, Man and Cybernetics. Tucson, 7-10, October, 2001.

BORTOLUZZI, S. C.; ENSSLIN, S. R.; LYRIO, M. V. L.; ENSSLIN, L. Proposta de um Modelo Multicritério de Avaliação de Desempenho Econômico-Financeiro para Apoiar Decisões de Investimentos em Empresas de Capital Aberto. Revista TECAP, v. 3, p. 92-100, 2009. 
CAMPOS, V. R.; ALMEIDA, A. T. Modelo multicritério de decisão para localização de Nova Jaguaribara com VIP Analysis. Pesquisa Operacional, v. 26, p. 91-107, 2006.

CÁÑEZ, L.; GARFIAS, M. Portfolio Management at the Mexican Petroleum Institute. Research Technology Management, v. 49, n. 4, p. 46, 2006.

CHEN, Y.; KILGOUR, D. M.; HIPEL, K. W. A case-based distance method for screening in multiple-criteria decision aid. Omega, v. 36, p. 373-383, 2008.

EDEN, C.; JONES, S.; SIMS, D. Messing about in problems. An informal structured approach to their identification and management. Journal of the Operational Research Society, v. 35, p. 269-270, 1984.

EISENHARDT, K. M.; BROWN, S. L. Competing on the Edge: Strategy as Structured Chaos. Harvard Business Press, 1998.

ENSSLIN, L.; DUTRA, A.; ENSSLIN, S. R. MCDA: a constructivist approach to the management of human resources at a governmental agency. International Transactions in Operational Research, v. 7, p. 79-100, 2000.

ENSSLIN, L.; GIFFHORN, E.; ENSSLIN, S. R.; PETRI, S. M.; VIANNA, W. B.; Avaliação do Desempenho de Empresas Terceirizadas com o Uso da Metodologia Multicritério de Apoio à Decisão- Construtivista. Revista Pesquisa Operacional, v. 30, n. 1, p. 125-152, Janeiro a Abril de 2010. Versão impressa ISSN 0101-7438 / versão online ISSN 1678-5142.

ENSSLIN, L.; QUEIROZ, S. G.; GRZEBIELUKAS, C.; ENSSLIN, S. R.; NICKEL, E.; BUSON, M. A.; BALBIM, A. J. Identificação das necessidades do consumidor no processo de desenvolvimento de produtos: uma proposta de inovação ilustrada para o segmento automotivo. Revista Produção Online, v. 21, p. 1-10, 2011.

ENSSLIN, L.; LONGARAY, A. A.; MACKNESS, J. R. Decision Support System to Aid a Patient with Stress to Identify Opportunities to Improve her Quality of Life. Proceedings of the Annual International Scientific Conference Operations Research, p. 7-9, 2005

ENSSLIN, L.; MONTIBELLER, G.; NORONHA, S. M. Apoio à decisão: metodologias para estruturação de problemas e avaliação multicritério de alternativas. Insular. Florianópolis, 2001.

ENSSLIN, S. R. A Incorporação da Perspectiva Sistêmico-Sinergética na Metodologia MCDA-Construtivista: Uma Ilustração de Implementação. Dissertação doutorado. Programa de Pós-Graduação em Engenharia de Produção - PPGEP, Universidade Federal de Santa Catarina - UFSC, Florianópolis, 2002.

GRZEBIELUCKAS, C.; BUSON, M. A.; QUEIROZ, S. G.; ENSSLIN, L.; ENSSLIN, S.; NICKEL, E.; BALBIM, A. J. Instrumento para identificação das necessidades do consumidor no processo de desenvolvimento do design: Um estudo ilustrado com o projeto de um automóvel. Gestão \& Produção, v. 18, n. 2, p. 337-350, 2011. 
Disponível em: < http://www.scopus.com/inward/record.url?eid=2-s2.079960752985\&partnerID=40\&md5=da08a111040ed9e5626d9cb98c161913 >.

GOMES, C. F. S. Using MCDA methods THOR in an application for outranking the ballast water management options. Pesquisa Operacional, v. 25, p. 11-28, 2005.

JIAO, J.; TSENG, M. M. Customizability analysis in design for mass customization. Computer-Aided Design, v. 36(8), p. 745-757, 2004.

KEENEY, R. L. Value-Focused Thinking: A Path to Creative Decisionmaking. Harvard University Press, Massachusetts, 1992.

LACERDA, R. T. O.; ENSSLIN, L.; ENSSLIN, S. R. A performance measurement framework in portfolio management: A constructivist case. Management Decision, v. 49, n. 4, p. 648-668, 2011a.

LACERDA, R. T. O.; ENSSLIN, L.; ENSSLIN, S. R. A performance measurement view of IT project management. International Journal of Productivity and Performance Management, v. 60, n. 2, p. 132-151, 2011b.

LACERDA R. T.; ENSSLIN, L.; ENSSLIN, S. R. Um Estudo de Caso sobre gerenciamento de portfólio de projetos e apoio à decisão multicritério. Revista Gestão Industrial, v. 6, p. 1-29, 2010.

LANDRY, M. A Note on the Concept of 'Problem'. Organization Studies, v. 16, p. 315343, 1995.

MONTIBELLER, G.; SHAW, D.; WESTCOMBE, M. Using decision support systems to facilitate the social process of knowledge management. Knowledge Management Research and Practice, v. 4, n. 2, p. 125-137, 2006.

ROBERTS, F. S. Measurement theory. Addison-Wesley Reading, Massachusetts, 1979.

ROY, B. Decision science or decision-aid science? European Journal of Operational Research, v. 66, p. 184-203, 1993.

ROY, B. Decision-aid and decision making. In: Readings in Multiple Criteria Decision Aid [edited by Bana e Costa, C.A.], Springer, p. 17-35, 1990.

ROY, B. Multicriteria Methodology for Decision Aiding. Kluwer Academic Publishers, 1996.

ROY, B. On operational research and decision aid. European Journal of Operational Research, v. 73, p. 23-26, 1994.

ROY, B. Paradigms and Challenges, Multiple Criteria Decision Analysis - State of the Art Survey. In: Multicriteria Decision Analysis: state of the art survey. Springer Verlag, p. 3-24, 2005. 
ROY, B.; VANDERPOOTEN, D. The european school of MCDA: emergence, basic features and current works. Journal of Multi-Criteria Decision Analysis, v. 5, p. 22-38, 1996.

SILVEIRA, C. F. Avaliação de desempenho com foco no Marketing de relacionamento: um estudo de caso. Tese mestrado. Programa de Pós-Graduação em Engenharia de Produção - PPGEP, Universidade Federal de Santa Catarina UFSC, Florianópolis, 2007.

VIANNA, W. B.; ENSSLIN, L. O design na pesquisa quali-quantitativa em engenharia de produção - questões epistemológicas. Revista Produção Online, 2008.

TSENG, M. M.; JIAO, J. A Pragmatic Approach to Product Costing Based on Standard Time Estimation, International Journal of Operations \& Production Management, v. 19, n. 7, p. 738-754, 1999.

ZAMBON, K. L.; CARNEIRO, A. A. de F. M.; SILVA, A. N. R. da; NEGRI, J. C. Análise de decisão multicritério na localização de usinas termoelétricas utilizando SIG. Pesquisa Operacional, v. 25, p. 183-199, 2005. 